DOI: https://doi.org/10.18485/bells.2016.8.5

UDC: 811.111'367.624

UDC: 811.113.4'367.624

\author{
Richard Madsen* \\ Aalborg University \\ School of Culture and Global Studies \\ Department of English Business Communication \\ Denmark
}

\title{
RELATIVE CLAUSES IN SECOND LANGUAGE ACQUISITION
}

\begin{abstract}
Despite English and Danish being similar languages, even Danes who are proficient in English (university students of English) seem to have difficulties with relative clauses in English. This paper explores this issue by first making a detailed contrastive analysis of English and Danish, and then comparing the hypotheses drawn from this analysis to a corpus of texts, consisting of essays and summaries in English, and translations from Danish into English, written by Danish university students. The corpus study is supplemented by questionnaires testing the students' abilities to form relative clauses in English. It is found that the types of errors predicted from the contrastive analysis do occur to a large extent in the students' texts and in the questionnaire responses.
\end{abstract}

Keywords: relativization, second language acquisition, syntax

E-mail address: richard@cgs.aau.dk 


\section{Introduction}

The main purpose of the author's $\mathrm{PhD}$ project is to document and analyse the challenges that Danish university students (primarily freshmen) face in their acquisition of written English and in their learning of descriptive/ theoretical grammar. The project has its point of departure in the interlanguage and contrastive hypotheses (Selinker 1972; Lado 1957, Corder 1981, Ellis 2009, 2012, Jarvis 2011), and instances of the influence of the L1 (Danish) on the L2 (English) in the students' writings are indeed ubiquitous (Madsen 2014, 2015, forthcoming). In this paper, the focus is on the acquisition of English relative clauses.

The impetus to this study was the informal observation that Danish university students of English seemed to have trouble with the use of whose as a relative pronoun. It was surprising since Danish has a cognate (hvis), which is used in the exact same way syntactically as whose. This phenomenon was investigated in Madsen (2015). During that project, further problem areas with the use of relative pronouns by Danes were identified, and the present paper focuses on these areas, expounded in the next section.

\section{Theory and hypotheses}

As mentioned in the introduction, the theoretical approach of this paper is the contrastive hypothesis, i.e. a learner's L1 influences the learner's acquisition of the L2 (Lado 1957). Since Lado's seminal work it has been recognised (Pavlenko et al. 2002, Jarvis et al. 2008, Jarvis 2011, Odlin 1989) that not only the learner's mother tongue can influence the language being learnt, but also other languages that the learner has acquired previously. Such a possible non-Danish-language influence has been ignored in the present study although some of the informants are descendants of immigrants and have thus been raised bilingually. One reason for ignoring this possible influence is that there are only a few early-childhood bilinguals among the informants, and consequently, it is not possible to make a reliable statistical analysis of this group compared to the monolingually raised informants, especially since the former group is heterogeneous representing very different parallel L1s, such as Arabic, Turkish, Vietnamese, etc. Another reason is that all these informants have grown up in Denmark and attended Danish schools, and their Danish is 
on a par with that of their monolingually raised peers. By not excluding the bilingually raised informants, this study describes the "average" student citizen of Denmark, and not an idealised group of students raised monolingually in Danish. On the other hand, an exchange student was excluded from the study even though her written Danish compared favourably with that of native Danes, because she did not grow up in and was never a resident of Denmark.

The hypotheses that were tested in this work were based on a contrastive comparison, which is explicated below (Huddleston and Pullum 2002, Togeby 2003). Both being Germanic languages, Danish and English are expectably similar with respect to the formation of relative clauses. The most frequent type of relative clause in Danish is the finite postmodifying relative clause introduced by a relativizer. Just as in English, the relativizer can be omitted when it is the direct or indirect object or is part of a prepositional construction. When the relativizer is part of a prepositional construction, the preposition is stranded most frequently ${ }^{1}$. Danish allows non-finite postmodifying clauses too in the same way as English does; however, these are used much less frequently than in English (Hjulmand and Schwarz 2012). On the other hand, Danish allows non-finite premodifying clauses too, much like German, although such constructions are restricted to legal language or legalese. ${ }^{2}$ The focus of this study is - as mentioned in the introduction - on the use of relativizers; consequently, it concerns itself with the use of finite postmodifying relative clauses.

Table 1 lists the relativizers of Danish. It is disputed whether all or in fact any of them can be called relative pronouns (Lehmann 1984, Togeby 2003); however, that discussion is beside the point of this study. Relativizers that correspond to where, why and when were ignored in this study because they are limited to antecedents with special features, such as place, reason and time. However, a study is planned to investigate the use of where by Danes because its Danish cognate hvor has a much wider

\footnotetext{
${ }^{1}$ In the case of the relativizer som, the preposition is invariably stranded. In the case of hvem and hvilken, it is typically preposed, and when the relativizer would be hvad, the cognate of what, it and the relativizer are fused. E.g., om hvad becomes hvorom 'whereabout'.

2 There is some evidence that non-finite premodifying clauses are difficult for people not trained in legal language to comprehend. A survey that was supposed to test the informants' ability to translate Danish sentences containing non-finite premodifying clauses into English failed because many informants apparently did not even understand the Danish originals even though these were rather simple clauses in which one of the NPs merely contained a non-finite premodifying clause.
} 
application than where, and it seems for this reason that Danes sometimes misuse where when writing English.

Table 1: Relativizers in modern Danish

\begin{tabular}{|c|c|c|}
\hline Relativizer & Antecedent & $\begin{array}{c}\text { Syntactic function in relative } \\
\text { clause }\end{array}$ \\
\hline som & any except a clause & any except possessor \\
\hline der & any except a clause & only subject \\
\hline hvilket & a clause & any except possessor \\
\hline hvad & a clause & only subject \\
\hline hvad der & a clause & any except possessor possessor and subject \\
\hline hvilken & inanimate except a clause & any except possessor \\
\hline hvem & animate & only possessor \\
\hline hvis & any &
\end{tabular}

Hvilken and hvem are the cognates of which and whom, respectively, and are almost exclusively used as interrogative pronouns, only seldom as relativizers in modern Danish. If hvilken is indeed used, it agrees with its antecedent in grammatical gender and number. Hvilket is the neuter singular of hvilken; however, in modern Danish it is almost only used with a clausal antecedent. In any case, hvilken and its declensions can only refer to inanimate antecedents. Hvem is originally the dative form of the animate interrogative/relative pronoun; however, it has completely replaced the original nominative form hvo. Hvo appears only in a couple of proverbs in modern Danish. Hvem can only refer to animate antecedents. Hvis is the genitive of hvo/hvem; however, it can - just as the English whose - also be used with inanimate antecedents. Som and der are the relativizers that are used by far the most frequently in modern Danish. It must be noted, however, that som and der are also the translation equivalents of as and there, respectively. Der is of course not only the translation equivalent of there, but also its cognate. Both som and der are indifferent to animacy and can refer to any antecedents except clauses. ${ }^{3}$

3 In apparently careless writing, som is sometimes found referring to a clausal antecedent. Der has not been attested in this function regardless of writing style. 
Danish does not distinguish between restrictive and non-restrictive relative clauses as far as the relativizer itself is concerned. In other words, there is no difference in the choice of relativizer similar to the distinction in English between that on the one hand and who/which on the other hand. Nor is the distinction between parenthetical and restrictive relative clauses reflected consistently in punctuation, i.e. comma usage. The Danish Language Council does not recommend the use of comma before restrictive relative clauses, similarly to the standard orthographic rule in English, which precludes the use of comma before restrictive relative clauses. However, this recommendation has existed only since 1996, and the comma is still allowed before any subordinate clause regardless of its nature. Before 1996, it was obligatory to place a comma before every subordinate clause, as in German. In the experience of the author of this paper, who has educated teachers of Danish since 2000 and has given countless public lectures on the use of punctuation in Danish since 2009, the abovementioned recommendation has gone unnoticed by both the general public and teachers of Danish. Consequently, most Danes are completely unaware that there is at all a difference between parenthetical and restrictive relative clauses, and the teaching of this distinction in English is a perpetual challenge.

Based on the contrastive analysis above, it is expected that negative transfer from Danish to English occurs in the following cases, which constitute the hypotheses for this study:

1. Which and who may be confused with respect to the animacy of the antecedent because the most frequently used relativizers in Danish (som and der) do not make this distinction;

2. Who and whom may be confused in the way that whom is used erroneously as the subject of the relative clause since whom has an obvious cognate in Danish (hvem), which can readily be used as the subject in modern Danish, whereas who does not have a widely known cognate at all anymore;

3. Entirely wrong words may be used, i.e. as and there in place of a proper relativizer because as and there are also translation equivalents of the Danish words most frequently used as relativizers, namely som and der. Naturally, the correct use of as as relativizer is not considered a mistake; 
4. Parenthetical and restrictive relative clauses may be confused with respect to both the choice of relativizer (that vs. who/which) and the use of comma.

Even though it is formulated above, the present paper does not concern itself with hypothesis 4 because it is planned to dedicate a separate study to the use of punctuation in English by Danes. The reason for devoting a separate paper to that issue is that as much as about $20 \%$ of all mistakes detected in the writings of Danish students have to do with punctuation, especially with the use of comma (Madsen 2014).

\section{Method}

For the testing of the hypotheses outlined above, a group of freshmen of English Business Communication at Aalborg University, Denmark served as informants. Two types of data were gathered: results of a questionnaire specifically developed for this study and error analysis of texts that the students had written independently of this study (Corder 1981, Oppenheim 1992). The questionnaire contained a set of gap-filling and a set of multiplechoice questions, in both of which the students had to insert the appropriate relativizer into matrix clauses, together with an appropriate preposition if needed. The two sets of questions will be henceforth referred to as the gapfilling and multiple-choice test, respectively. The tests were administered electronically with the help of the quiz functionality of the Moodle software package, which is used for all study-related administrative and educational purposes in Aalborg University. The questions were presented to the informants in a random order, so no two informants received the questions in the same order. The set of answers to the multiple-choice questions was also randomised and contained besides the correct answer both wrong, but sensible answers (i.e. answers with wrong relativizers or wrong prepositions) and nonsensical answers (i.e. answers that did not even contain a relativizer, including of course the words as and there). Neither the relativizer that nor the zero relativizer was part of the set of answers to the multiple-choice questions in order to force the informants to choose between who and which (Table 2). With one exception, the zero relativizer was never a viable choice to the gap-filling questions; thus empty responses automatically counted as mistakes. Because of the rigidity of 
the quiz function of Moodle, prepositions always had to be preposed the relativizer, never stranded. Table 2 lists the questions of both the multiplechoice and gap-filling tests, and Table 3 shows the answers to the multiplechoice questions. The tests actually contained four more questions each that concerned topics outside the scope of this study; they are thus not reported here.

Table 2: The questions of the tests

\begin{tabular}{|c|c|c|}
\hline $\begin{array}{l}\text { Relativizer } \\
\text { sought }\end{array}$ & $\begin{array}{l}\text { Multiple-choice } \\
\text { questions }\end{array}$ & Gap-filling questions \\
\hline Who & $\begin{array}{l}\text { She misses her grandma, } \\
\{\} \text { died a couple of weeks } \\
\text { ago, very much. }\end{array}$ & $\begin{array}{l}\text { I watch videos featuring a chemist, } \\
\{\} \text { is now my new hero, on YouTube. }\end{array}$ \\
\hline Whom & $\begin{array}{l}\text { Jackie Chan, }\{\} \text { I admire, } \\
\text { is a famous actor. }\end{array}$ & $\begin{array}{c}\text { Prof. Poliakoff, }\{\} \text { I watch on } \\
\text { YouTube, is an excellent chemist. }\end{array}$ \\
\hline $\begin{array}{c}\text { Which as direct } \\
\text { object }\end{array}$ & $\begin{array}{l}\text { I sold the sofa }\{\} \text { no one } \\
\text { liked very much. }\end{array}$ & $\begin{array}{l}\text { I like the videos }\{\} \text { Prof. Poliakoff } \\
\text { and his team make. }\end{array}$ \\
\hline Which as subject & $\begin{array}{l}\text { I bought a new sofa, } \\
\{\} \text { was on sale in IKEA. }\end{array}$ & $\begin{array}{l}\text { I like to watch videos } \\
\{\} \text { feature science. }\end{array}$ \\
\hline to whom & $\begin{array}{c}\text { My students, }\{\} \text { I give } \\
\text { many exercises, are getting } \\
\text { better and better. }\end{array}$ & $\begin{array}{c}\text { Peter, }\{\} \text { Julie has told a sad story, } \\
\text { is a good listener. }\end{array}$ \\
\hline from whom & $\begin{array}{l}\text { Prof. Poliakoff is someone } \\
\{\} \text { you can learn a lot. }\end{array}$ & $\begin{array}{c}\text { She misses her grandma, }\{\} \text { she has } \\
\text { inherited a sofa. }\end{array}$ \\
\hline about which & $\begin{array}{c}\text { The sofa }\{\} \text { you may have } \\
\text { read elsewhere doesn't } \\
\text { exist. }\end{array}$ & $\begin{array}{l}\text { The elements and molecules, } \\
\{\} \text { Prof. Poliakoff lectures in his } \\
\text { videos, are very exciting. }\end{array}$ \\
\hline of which & $\begin{array}{l}\text { Nordrhein-Westfalen, the } \\
\text { English name }\{\} \text { is North } \\
\text { Rhine-Westphalia, is my } \\
\text { favourite federal state of } \\
\text { Germany. }\end{array}$ & $\begin{array}{l}\text { Vatican City, the major "industry" } \\
\{\} \text { is religion, is the smallest state } \\
\text { in the world. }\end{array}$ \\
\hline
\end{tabular}


Table 3: The set of answers to the multiple-choice questions

\begin{tabular}{|c|c|c|c|c|c|c|}
\hline as & there & which & who & whom & whose & where \\
\hline why & What & from whom & because & to whom & of which & about which \\
\hline
\end{tabular}

In order also to have a textual base for the study, a body of texts written by freshmen in the five academic years from the autumn of 2010 to the spring of 2015 was analysed for errors in the use of relative clauses. The informants participating in the test described above, and the informants providing the texts are two different groups since the tests were conducted in the autumn of 2015. The texts were composed in the course Production of Written Texts within three genres: short composition (e.g. business letters, ads) in English, summarising in English of an English original, and translation from Danish into English.

\section{Analysis}

In the first two subsections, the results of the two tests are presented. The responses were assigned the following six labels: correct, wrong form but correct animacy, Danism, wrong animacy, whom instead of who, and empty or nonsensical. A response was classified correct when it was the correct relativizer, spelled correctly, and if necessary, accompanied with the correct preposition. The label wrong form but correct animacy covers cases in which the relativizer was misspelled, accompanied with an incorrect preposition or did not have a preposition when one was called for. A response was classified as Danism when it was as or there (see hypothesis 3 ). The label wrong animacy covers cases in which a relativizer with the wrong animacy was used regardless whether it was spelled correctly or had the correct preposition (see hypothesis 1). The label whom instead of who covers cases in which whom had been used erroneously as subject. This label is only relevant for one question in either test (see hypothesis 2 ). The label empty or nonsensical covers cases in which the response did not contain a relativizer at all. Since only 81 informants participated in the tests, the percentages are rounded to the nearest whole number. That is why the sum of the numbers in one row may not equal 100; nevertheless, all responses are accounted for. 


\subsection{Results of the gap-filling test}

The gap-filling test was used to see if the informants were able to insert the right (form of the) relativizer together with a preposition if needed. Table 4 shows the test results in percentage of the total number of responses.

Table 4: The results of the gap-filling test

\begin{tabular}{|c|c|c|c|c|c|c|}
\hline $\mathrm{n}=81$ & \multicolumn{5}{|c|}{ Response categories } \\
\hline $\begin{array}{c}\text { Target } \\
\text { relativizers } \\
\text { and } \\
\text { prepositions }\end{array}$ & correct & $\begin{array}{c}\text { wrong form } \\
\text { but correct } \\
\text { animacy }\end{array}$ & Danism & $\begin{array}{c}\text { wrong } \\
\text { animacy }\end{array}$ & $\begin{array}{c}\text { whom } \\
\text { instead } \\
\text { of } \text { who }\end{array}$ & $\begin{array}{c}\text { empty or } \\
\text { nonsensical }\end{array}$ \\
\hline Who & 79 & 1 & 0 & 7 & 10 & 2 \\
\hline who(m) & $89^{4}$ & 2 & 0 & 5 & n.a. & 2 \\
\hline $\begin{array}{c}\text { which as } \\
\text { direct object }\end{array}$ & $86^{5}$ & 0 & 0 & 6 & n.a. & 7 \\
\hline $\begin{array}{c}\text { which as } \\
\text { subject }\end{array}$ & $77^{6}$ & 1 & 0 & 1 & n.a. & 20 \\
\hline to whom & 15 & 72 & 0 & 5 & n.a. & 9 \\
\hline from whom & 1 & 83 & 0 & 10 & n.a. & 6 \\
\hline about which & 10 & 74 & 0 & 1 & n.a. & 15 \\
\hline of which & 9 & 59 & 2 & 2 & n.a. & 27 \\
\hline
\end{tabular}

The low number of correct answers in the case of to whom can be explained by interference from Danish since Danish does not require the use of a preposition when the relativizer is to function as indirect object in its relative clause. The use of the preposition til, the counterpart of to, is allowed, but seemingly disfavoured. However, the other cases of a

$465 \%$ of the informants responded with who, and $23 \%$ with whom. Both answers were accepted as correct.

$553 \%$ of the informants responded with that, and 33\% with which. Both answers were accepted as correct. No informants used the zero relativizer.

$642 \%$ of the informants responded with which, and $36 \%$ with that. Both answers were accepted as correct. 
relativizer combined with a preposition, which also had a low number of correct responses, cannot be explained in such a straightforward manner because Danish also requires the use of a preposition in these cases. Nevertheless, no preposition was provided at all in the vast majority of the responses. The only possible explanation with reference to Danish may be that modern Danish strongly dejects prepositions combined directly with a relativizer; a stranded preposition is clearly the favoured choice.

\subsection{Results of the multiple-choice test}

The multiple-choice test was taken by 81 informants. Table 5 shows the test results in percentage of the total number of responses.

Table 5: The results of the multiple-choice test

\begin{tabular}{|c|c|c|c|c|c|c|}
\hline n=81 & \multicolumn{5}{|c|}{ Response categories } \\
\hline $\begin{array}{c}\text { Target } \\
\text { relativizers } \\
\text { and } \\
\text { prepositions }\end{array}$ & correct & $\begin{array}{c}\text { wrong } \\
\text { form but } \\
\text { correct } \\
\text { animacy }\end{array}$ & Danism & $\begin{array}{c}\text { wrong } \\
\text { animacy }\end{array}$ & $\begin{array}{c}\text { whom } \\
\text { instead } \\
\text { of } \text { who }\end{array}$ & $\begin{array}{c}\text { empty or } \\
\text { nonsensical }\end{array}$ \\
\hline who & 88 & 0 & 1 & 2 & 7 & 1 \\
\hline who(m) & 967 & 0 & 1 & 1 & n.a. & 1 \\
\hline $\begin{array}{c}\text { which as direct } \\
\text { object }\end{array}$ & 70 & 7 & 2 & 9 & n.a. & 11 \\
\hline $\begin{array}{c}\text { which as } \\
\text { subject }\end{array}$ & 91 & 1 & 7 & 0 & n.a & 0 \\
\hline to whom & 49 & 42 & 0 & 9 & n.a. & 0 \\
\hline from whom & 69 & 20 & 0 & 9 & n.a. & 2 \\
\hline about which & 30 & 35 & 25 & 7 & n.a. & 4 \\
\hline of which & 31 & 65 & 2 & 1 & n.a. & 0 \\
\hline
\end{tabular}

\footnotetext{
$757 \%$ of the informants responded with who, and $40 \%$ with whom. Both responses were accepted as correct.
} 
As in the case of the gap-filling test, the items that required a relativizer with a preposition proved to be the most challenging ones although to a lesser degree. Also in the multiple-choice test, the prevalent problem was the omission of the preposition - even though required in Danish as well not the use of a wrong preposition. On the other hand, the multiple-choice test elicited considerably fewer empty or nonsensical responses than the gap-filling test did. Contrary to this, the multiple-choice test resulted in many more Danisms in the responses than the gap-filling test did. The results of the two tests are similar to each other as for the wrong choice of relativizer with respect to the antecedent's animacy, and the erroneous use of whom as subject.

\subsection{Results of the error analysis}

The error analysis of the corpus was used to see to what extent in actual practice the students made mistakes with relativizers with regard to the hypotheses posited in this study. 1421 texts in English containing more than 370000 words were analysed. Of all the mistakes that were detected, roughly $1.09 \%$ have to do with relativization. This error type is therefore not the most critical one by and large. Table 6 shows the summary of the error analysis.

Table 6: Results of the error analysis

\begin{tabular}{|c|c|c|c|c|}
\hline \multirow{2}{*}{ Text type } & $\begin{array}{c}\text { Relativizer } \\
\text { used }\end{array}$ & $\begin{array}{c}\text { Number of } \\
\text { instances }\end{array}$ & $\begin{array}{c}\text { Wrong } \\
\text { animacy }\end{array}$ & $\begin{array}{c}\text { Wrong } \\
\text { case }\end{array}$ \\
\hline \multirow{3}{*}{$\begin{array}{c}\text { Translation from Danish } \\
\text { into English }\end{array}$} & who & 441 & $26(5.86 \%)$ & n.a. \\
\cline { 2 - 5 } 539 texts, 174 000 words & whom & 16 & 0 & $15(94 \%)$ \\
\cline { 2 - 5 } & which & 996 & $1(0.10 \%)$ & n.a. \\
\cline { 2 - 5 } & Danism & 15 & n.a. & 0 \\
\hline \multirow{3}{*}{$\begin{array}{c}\text { Summary } \\
408 \text { texts, } 97000 \text { words }\end{array}$} & who & 361 & $4(1.11 \%)$ & n.a. \\
\cline { 2 - 5 } & whom & 7 & $3(0.82 \%)$ & 3 (43\%) \\
\cline { 2 - 5 } & which & 368 & n.a. & 0 \\
\cline { 2 - 5 } & Danism & 0 & & 0 \\
\hline
\end{tabular}




\begin{tabular}{|c|c|c|c|c|}
\hline \multirow{3}{*}{$\begin{array}{c}\text { Free composition } \\
474 \text { texts, } 107000 \text { words }\end{array}$} & who & 80 & $5(63 \%)$ & n.a. \\
\cline { 2 - 5 } & whom & 8 & $1(13 \%)$ & $5(63 \%)$ \\
\cline { 2 - 5 } & which & 402 & 0 & n.a. \\
\hline \multirow{2}{*}{$\begin{array}{c}\text { Altogether } \\
1421 \text { texts, 370 000 words }\end{array}$} & 2 & $\begin{array}{c}2696 \\
(0.56 \% \\
\text { Danism) }\end{array}$ & $40(1.49 \%)$ & $23(74 \%)$ \\
\hline
\end{tabular}

Instances of that, why, where, when and whose used as relativizer were ignored in this study since they are not covered by the hypotheses. Instances of wrong or non-use of a preposition with a relativizer were also ignored because those errors had been classified as preposition errors and thus fell outside the scope of this study.

The sum of all the instances of the relativizers also includes Danisms (the erroneous use of as and there), which constitute $0.56 \%$ of all the instances of the relativizers used by the students and investigated in this study. Danisms were ignored in the calculation of the percentages of the instances of wrong choice of animacy since the underlying Danish words do not distinguish between animate and inanimate antecedents. The possibility of wrong case usage, on the other hand, does exist with Danisms. As can be seen in Table 1, der can only be used as the subject of the relative clause. Thus, if there were used in a function other than the subject, it could be construed as an error in case even though der and som can hardly be considered declensional forms. In any case, no such errors were detected, and thus, the percentage of the sum of the instances of wrong choice of case reflects only the erroneous use of whom as subject in proportion to all instances of whom as relativizer.

It seems that who is more often used erroneously with inanimate antecedents than which is used with animate antecedents. One partial explanation is that the students often use who with reference to a firm or company, but with the verb in the singular. These mistakes were classified as mistakes with the relativizer for this study; however, in principle, they could also be categorised as mistakes with subject-verb agreement. If so, who may not be significantly more misused than which. 


\subsection{Summary of the analyses}

Table 7 summarises the main results of the tests and the error analysis.

Table 7: Summary of the tests and the error analysis

\begin{tabular}{|c|c|c|c|c|}
\hline \multicolumn{2}{|c|}{} & wrong animacy & wrong case & Danism \\
\hline \multicolumn{2}{|c|}{ Error analysis } & $1.49 \%$ & $74 \%$ & $0.56 \%$ \\
\hline \multirow{2}{*}{ Test } & multiple-choice & $4.8 \%$ & $7 \%$ & $3.8 \%$ \\
\cline { 2 - 5 } & gap-filling & $4.8 \%$ & $11 \%$ & $0.3 \%$ \\
\hline
\end{tabular}

The confusion of the relativizer with respect to the antecedent's animacy is more pronounced in the tests than in actual writing, and it does not seem to matter how the students are tested. Whether this difference is significant or not, is impossible estimate. In any case, it is somewhat consoling that the students do better in the actual use of English than in artificial tests.

The erroneous use of whom as subject is, unfortunately, much more pronounced in actual writing than in either of the tests, which seem to yield similar results. Since whom is not used very often, as shown in Table 6 , one might argue that it does not cause so many mistakes in practice, either. Nevertheless, it is somewhat worrying that whenever the students do attempt to use it, they do so almost invariably erroneously. Thus, it may warrant the introduction of some extra exercises in class.

The erroneous use of as and there, here called Danism, has similarly low prevalence both in actual writing and in the gap-filling test. The relatively high occurrence of this error type in the multiple-choice test might be due to the fact that the students are explicitly presented with as and there as possible answers, and this might elevate the students' inclination to use them. In any case, since the prevalence of this error type is so low in practice, it does not seem to be the biggest cause for concern.

\section{Conclusion}

Generally, all the three hypotheses that were posited in this study were verified, to differing degrees. The most significant of the hypotheses is number 2, the erroneous use of whom as subject. Although whom is not a 
word that is used frequently by the students, also not when it could and ought to be used in an academic text, it is almost always used erroneously when it is used. Thus, it seems to deserve increased attention in the teaching of academic and scientific English to Danish students.

It is debatable how much one should worry because of the fact that about $1.5 \%$ of the relativizers used by Danish students show a mismatch with respect to the animacy of the antecedent. In an informal interview, some of the informants acknowledged that this distinction is so basic that one ought not to make a mistake with it. On the other hand, the interviewees contended that the mistakes were not due to lack of knowledge, but to lack of proper attention when doing their assignments. If this claim is warranted, it may not be necessary to focus on the technicalities of who and which in class, but rather on training for paying closer attention when writing and editing written work.

The erroneous use of as and there, here called Danism, merits the least concern since it has a rather low occurrence in the actual writing of the students. Its relatively frequent occurrence in the multiple-choice test is likely attributable to the artificial and biased nature of the test.

A result that was not anticipated has also emerged from the tests used in this study. Using relativizers with preposed, not stranded prepositions seems to be rather challenging for the students. The error analysis can neither corroborate nor falsify this finding because this issue was not known when the error analysis was performed. Nevertheless, based on the tests, practising the use of relativizers with prepositions would to be a very good idea.

\section{References}

Corder, P. (1981). Error Analysis and Interlanguage. Oxford University Press.

Ellis, R. (2009). Implicit and explicit knowledge in second language learning, testing and teaching. Buffalo: Multilingual Matters.

Ellis, R. (2012). Second Language Acquisition. Oxford: Oxford University Press.

Hjulmand, L., and H. Schwarz (2012). A Concise Contrastive Grammar of English. Frederiksberg: Samfundslitteratur. 
Huddleston, R. and G. K. Pullum (2002). The Cambridge Grammar of the English Language. Cambridge: Cambridge University Press.

Jarvis, S. and A. Pavlenko (2008). Crosslinguistic influence in language and cognition. New York \& London: Routledge.

Jarvis, S. (2011). Conceptual transfer: Crosslinguistic effects in categorization and construal. Bilingualism: Language and Cognition 14 (1), 2011, 1-8.

Jarvis, S. (2011). “Conceptual transfer: Crosslinguistic effects in categorization and construal" in Bilingualism: Language and Cognition 14 (1), 2011, $1-8$.

Lado, R. (1957). Linguistics across Cultures. Ann Arbor: The University of Michigan Press.

Lehmann, C. (1984). Der Relativsatz. Tübingen: Gunter Narr Verlag.

Madsen, R. (2014). "Correlation between theoretical knowledge of grammar and performance in the production of written texts". In Multidisciplinary Perspectives on Language Competence edited by Lotte Dam and Rita Cancino. Aalborg: Aalborg University Press.

Madsen, R. (2015). "The accessibility hierarchy of relativization in second language acquisition" In Journal of Foreign Language Teaching and Applied Linguistics 1(3), 2015.

Madsen, R. (forthcoming). "Challenges does word order pose. A study of Danish speakers' difficulties with English syntax". Paper presented at PhD Student Conference Odense, Denmark in June 2015.

Odlin, T. (1989). Language Transfer, Cross-linguistic influence in language learning. Cambridge: Cambridge University Press.

Oppenheim, A. N. (1992). Questionnaire design, interviewing and attitude measurement. London: Continuum.

Pavlenko, A. and S. Jarvis (2002). "Bidirectional transfer". Applied Linguistics, 23, 190-214.

Selinker, L. (1972). Interlanguage. International Review of Applied Linguistics, 10, 209-241.

Togeby, O. (2003). Fungerer denne sætning?Funktionel dansk sproglære. [Does this sentence work? A functional grammar of Danish]. Copenhagen: Gads Forlag.

Carlberg, Conrad. (2014). Statistical Analysis: Microsoft Excel 2013. Indianapolis: Que Publishing. Kindle Edition. 